\title{
Bus Rapid Transit Identity: An Overview of Current "Branding" Practice
}

\author{
Daniel Baldwin Hess, University at Buffalo \\ Alex Bitterman, Rochester Institute of Technology
}

\begin{abstract}
The emergence of new bus rapid transit (BRT) systems in recent years has prompted transit agencies across North America to establish new and unique identity programs that communicate various benefits of improved bus service. These identities and brands, however, rely largely on perception and emotional reaction, which are difficult to quantify. This lack of "hard data" makes the efficacy of identity systems and expenditures on them difficult to assess. This evaluation of $22 B R T$ identity programs examines the typical constructs used to establish BRT identity: visual identifiers, nominal identifiers, and color palette. Through analysis of these constructs, we find that when deployed consistently across a range of media, BRT identity may help to further build and reinforce a positive perception of BRT service and, by extension, a positive public image for public transit in general. We conclude that BRT identity must be flexible in design to accommodate future needs, plans for expansion, and technological evolution.
\end{abstract}

\section{Introduction}

Public transit is experiencing a renaissance of sorts in the United States, fueled by interest in and mandates for curbing urban sprawl, reducing traffic congestion, lessening automobile dependency, and a desire to better protect the natural envi- 
ronment from automobile pollution (Pucher 2001). Transit officials are working to capitalize on these changes in public consciousness, and many hope to increase the demand for public transit by improving the quality and quantity of service and, in particular, by implementing new bus rapid transit (BRT) systems, which offer passengers faster, more convenient, and more comfortable travel through service enhancements.

BRT emulates service quality offered by light rail transit (LRT) at a fraction of the infrastructural cost (Levinson 2003), and can later be useful as a means to phase in fixed transit infrastructure, such as light rail or heavy rail. Some distinguish BRT as "an incremental investment that may be the precursor to eventual implementation of rail" (Polzin and Baltes 2002, p. 60). Published research speculates that BRT, as a "new" mode of public transportation, has the potential to reduce travel times, attract new riders, and encourage transit-oriented development (Levinson et al. 2002). A Transit Cooperative Research Program report (TCRP 2003, p. 1) defines BRT in the following manner:

BRT is a flexible, rubber-tired rapid-transit mode that combines stations, vehicles, services, running ways, and intelligent transportation system (ITS) elements into an integrated system with a strong positive identity that evokes a unique image. BRT applications are designed to be appropriate to the market they serve and their physical surroundings, and they can be incrementally implemented in a variety of environments.

We believe that the term "flexible" in the preceding definition is nonspecific, and as such would substitute the term "scalar" to better underscore the incremental and progressive nature of BRT system implementation. Perhaps more important than the exactitude of the definition, however, is the inclusion of the words "strong positive image" and "unique identity." These phrases underscore the significance of and the demand for transit planners to devise a well-conceived and consistently deployed BRT identity program to shape public perception and acceptance of BRT as a viable mode of transport that can be distinguished from existing bus service. While the mention of identity in this report is noteworthy, of equal importance is our observation that the TCRP report offers no references to other studies about BRT identity. The report cites no exemplars of BRT identity as precedents, offers little guidance as to what constitutes a BRT identity program, nor does it define the constructs of a BRT identity program. We argue that the success of any new or improved transit service, such as BRT, is dependent on the creation of an effective identity program that captures public attention and effectively conveys informa- 
tion about the service to its current users and potential users. In the following section we develop a clearly articulated definition of BRT identity.

Because BRT is a relatively new mode of public transit, there is a pronounced lack of qualitative and evaluative research about this service. Instead, much research has focused on quantifiable measures, such as how investments in infrastructure, vehicles and facilities, operational improvements, and technology can provide the framework for BRT service that upgrades the performance of traditional bus systems (Hess, Taylor, and Yoh 2005; Levinson et al. 2002; Polzin and Baltes 2002). Other research projects have compared the capital costs of BRT versus light and heavy rail projects and concluded that operating flexibility and lower infrastructure and equipment costs make BRT an attractive option for the expansion of public transit in mid-sized cities (U.S. General Accounting Office 2001; Sislak 2000; Wilbur Smith 1999; Euclid Consultants 1995).

Additionally, qualitative evaluation and critical assessment of both transit identity programs and BRT identity programs are conspicuously absent from the literature. Previous public transit research has investigated marketing (Bond 1984; Price Waterhouse 1998; Rosenbloom 1998), market segmentation (Elmore-Yalch 1988; Kemp 1993; Reinke 1988) and consumer perception of transit (Wachs 1976). However, while such elements of public transit marketing programs have been studied separately, comprehensive investigation of how these components interrelate with consumer perception to formulate a comprehensive transit identity program has yet to be addressed.

Despite a gap in the literature and a lack of documented case studies of transit identity, the emergence of BRT provides a unique opportunity to change negative perceptions regarding public transit in North America. However, this task is challenging without reliable, quantifiable methods that measure perception of transit-related identity. Therefore, while the approach outlined in this research is appropriate for the current stage of maturity of BRT identity, we offer this method with the caveat that as BRT service evolves and as the modes of identity communication become more complex, more pervasive, and less overt, quantifiable assessment methods and measures specific to transit should be pursued.

Despite this, our evaluation examines the current practice and effectiveness of BRT identity systems using metrics previously used to assess the perception of public transit in general, along with widely accepted models used to assess the perception of corporate identities. Throughout this evaluation, we examine the practical and perceptual constructs of identity programs specific to BRT systems. 
Our assessment includes a clearly articulated definition of BRT identity through an examination of its derivative, corporate identity (which is both colloquially and erroneously referred to as its "brand"1); an examination of corporate identity as a precedent to BRT identity programs; and an evaluation of commonalities and trends among the representative BRT programs. Our findings lead us to argue that the desired increase in public transit ridership and the ultimate success of BRT systems depend on practical considerations of consumer perception of BRT identity.

\section{Bus Rapid Transit Identity \\ BRT Identity Defined}

A clear definition of our use of the term "BRT identity" requires differentiation between the concepts of identity, branding, marketing, and advertising.

Identity is a construct of recognition prescribed to an entity-a corporation, a system, an organization, and its component parts. Olins (1978) argues that corporate identity in objective terms is passive; identity is simply a mechanism to broadcast "being" or existence to a public, which helps to guide and shape public perception of that entity. Identity and the elements that constitute identity-logotypes, slogans, jingles, signature colors, marketing plans, advertising spots, and so forth-simply remind the public of the existence of a particular entity. The goal is to prompt recognition at a later date or in a different context (Olins 1990).

Branding is the application of similar constructs to a particular product or range of products. Branding is the junior cousin of corporate identity but is arguably the more pervasive and outstanding of the two. Brands and identities both provide a degree of recognition to an inanimate entity, commodity, or object. Branding generates allegiance and commonality between purveyors and consumers who are spatially removed from one another or who do not otherwise have a personal relationship (Olins 1990).

Marketing is the science of forming a strategy to create, advertise, and sustain a brand or identity. Marketing is a long-term and synergistic endeavor based on quantifiable data that aims to target specific market groups and to serve these groups as market forces demand. Market research identifies the wants and needs of the consumer and, as a result, brands and identities are often shaped with these wants and needs in mind. 
Advertising is the systematic practice of convincing a consumer. Advertising activities are clearly defined by a strategic marketing plan and draw from the resources of a clearly articulated corporate identity and product brand.

Increasingly, consumers react to advertising and subscribe to brands and identities because these modes of communication represent a desired way of life or a set of ideals (Bierut, Drenttel, and Heller 2002). The constructs, definitions, and perceptual issues related to branding, identity programs, marketing, and advertising are well documented in the literature and the popular press, and research indicates that contemporary consumers do indeed react to these seemingly ephemeral prompts. We believe that much in the same manner that brands help to underscore a broader parental identity and incite trust in inanimate consumer commodities (Balmer and Wilson 1998), BRT identity programs can help to create a distinct and positive public perception of BRT while cultivating trust and reinvigorating a positive reputation for bus service.

We formulate a working definition of BRT identity that encompasses visually communicated elements (that signal consumer wants, needs, and other behaviors), strategy, and impact on industrywide identity. Though measurable, BRT identity programs (herein BRT IdP) are perceptual constructs substantiated by the strategic deployment, placement, and management of communication design elements that allow people to distinguish and remember the unique qualities of a specific BRT service from other services offered by a parent transit agency, similar services from competing agencies, and other modes of transportation altogether. In our analysis, we evaluate BRT identity programs that feature a distinct combination of communicative visual and perceptual elements that follow in the tradition of broader identity programs as they are used to delineate a BRT line from other bus services and that highlight desirable service characteristics of BRT (see Table 1). Because of this complex interrelated nature of identity, branding, advertising, and marketing, and the potential far-reaching effects of these activities on broader transportation trends (both public and private), we opt to refer to our investigation as "BRT identity," rather than simply "BRT branding."

Visual design elements usually form the collective cornerstone of any identity program, and for BRT the principal visual element is typically the BRT name represented by a logo. The logo serves as a visual prompt signifying an identity (English 1998) and supports or is supported by other design elements such as typography, unique color palettes, illustrations, and icons. Well-managed identity programs ensure proper and consistent use of visual design elements across a broad range 


\section{Table 1. Corporate Identity, Brand, Marketing and Advertising Analogs for BRT}

\begin{tabular}{|l|l|l|}
\hline & Corporate & BRT \\
\hline Identity & $\begin{array}{l}\text { Corporation } \\
\text { (e.g., Proctor \& Gamble, Toyota) }\end{array}$ & $\begin{array}{l}\text { Parent transit agency or unique service } \\
\text { offering (branded separately) } \\
\text { (e.g., NFTA, Silver Line, Metro Rapid) }\end{array}$ \\
\hline Brand & $\begin{array}{l}\text { Product } \\
\text { (e.g., Tide, Ivory, Prius) }\end{array}$ & $\begin{array}{l}\text { Service offering } \\
\text { (e.g., the CTA “El”, NFTA MetroBus) }\end{array}$ \\
\hline Marketing & Stategic plan & Ridership plan \\
\hline Advertising & $\begin{array}{l}\text { Print, TV, and online advertising } \\
\text { (e.g., magazine and newspaper } \\
\text { advertisements, commercials) }\end{array}$ & $\begin{array}{l}\text { Collateral materials } \\
\text { (e.g., trip planner, service } \\
\text { announcements, schedules) }\end{array}$ \\
\hline
\end{tabular}

of outputs, media, and scale and characteristically define specific rules for use of color palette as well as the use of type, photographic images, and proper placement and management of a logo. The visual design components of a BRT IdP are usually deployed across a broad array of media at various scales; this approach can help to fully articulate an identity for a BRT system (and delineate BRT service from other services of a parent transit agency). BRT IdP can range from large-scale constructed design elements (shelter furniture and kiosk-based system maps) and large-scale environmental graphic design installations (shelter or stop signage and way-finding indicators) to smaller scale print publications (timetables and advertisements) and virtual applications (websites and television or video productions). The BRT IdP also may incorporate signature identifiers such as acronyms, formal or informal names, or graphic renditions of unique design features of BRT vehicles, iconic landscape features, or architectural landmarks. Figure 1 shows how components of a BRT IdP are communicated on a vehicle, the most common medium for communication of the BRT IdP.

\section{Overview of Transit Identity}

While BRT is relatively new, the creation of transit identity programs, and more broadly advertising, marketing, and branding public transit, is not a new endeavor. Early examples of transit identity usually served to reinforce the perceptions of a public enamored with the novelty and technological marvels of mechanized transport. Between 1910 and the late 1920s, London Transport expanded its bus and rail system and established an identity campaign that included "carefully designed lettering everywhere, and publicity, especially by posters, conveyed the message 


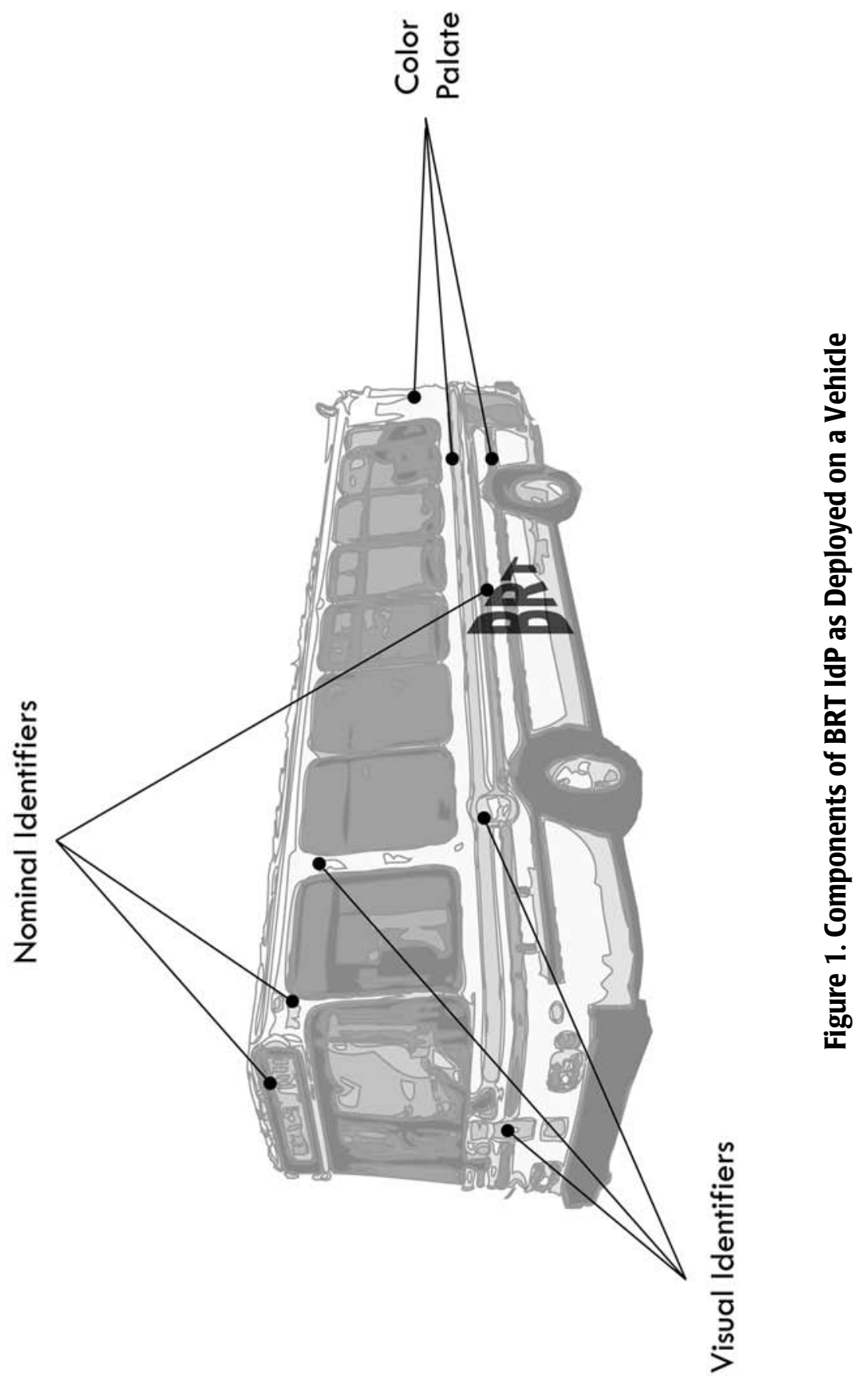


whenever the undertaking was addressing the public" (Baker and Robbins 1974, p. 250). Other notable achievements in the evolution of comprehensive transit identity programs include the 1890 colloquial adoption of the identifier " $T$ " to signify the subway in Boston (General Drafting Company and Massachusetts Bay Transportation Authority 1977), the iconic London Routemaster double-decked buses introduced in the late 1950s, Henry Beck's 1930 London Underground map, as well as more recent examples such as Massimo Vignelli's 1970 New York City Subway map (Heller and Pomeroy 1997) and signage system, and Vignelli's 1965 Washington Metro signage (Schrag 2001).

Contemporary transit officials perhaps seek to follow the successes of previous identity efforts, and in addition, many believe that BRT holds great potential because of its lower development and implementation costs (compared to rail transit), expandability, and operating scalability. ${ }^{2}$ Undoubtedly, this new service offering is ripe for a new marketing and consumer communication approach. An attraction of BRT is the promise that it can provide lower cost, high-quality service that retains current riders, attracts new riders (with speedier service), and gains political and taxpayer support for public transit (Polzin and Baltes 2002), and this support can be enhanced and extended through a thoughtfully developed and well-maintained BRT IdP.

The physical features of BRT vary but typically include some of the following: exclusive rights-of-way and direct routing, intersection and signal priority, improved passenger boarding, coordination with land-use planning, limited stations, frequent all-day service, prepaid fares, level boarding, unique vehicles, and the use of ITS (Levinson et al. 2002). For passengers, these features make a bus ride faster and more convenient. Typical service characteristics are highlighted in a variety of printed materials on the subject of BRT-published research, press releases, informational brochures, Internet websites-using terminology that identifies BRT as fast and convenient service that is distinct from traditional fixed-route transit. The efficacy of these physical manifestations of BRT service are discrete and are therefore easy to identify, clear to monitor, and straightforward to evaluate.

Other constructs, such as visual identity elements, are more subjective, harder to monitor, and difficult to assess, but can equally influence ridership. We describe these constructs as "perceptual." The perceptual image of public transit-that is, transit identity - can be defined as a function of vehicles, shelters, and identity. We expand on this relationship of elements to include a factor of identity deployment that is achieved through the diffusion of collateral materials-elements that 
communicate identity such as way-finding and directional signage, printed maps and schedules, corporate communications, advertisements, posters, flyers, and driver and transit police uniforms - as well as ephemeral materials, such as website design and television and radio advertisements. Consequently, we define transit identity in this manner:

Transit Identity $=f$ (vehicles, shelters and stations, collateral materials) where:

Vehicles $=$ color, design, functional usability, and cleanliness of vehicles

Shelters and stations = color, design, functional usability, and cleanliness of shelters

Collateral materials = proprietary publications such as timetables, system maps, etc.

Collectively, perceptual identifiers affect riders and potential riders on a subconscious or emotional level, and thus the efficacy of perceptual identifiers are more difficult to measure than a more clear-cut return on investment of physical features. However, if the trend with corporate identity and branding holds true for BRT identity, perceptual identifiers may be equally if not more important than physical features, and will undoubtedly act as the catalyst for changing stubborn public opinions about public transit in general. However, creating an effective identity for a BRT system is a difficult task for a variety of reasons:

- The hard-to-define nature of identity makes the creation and maintenance of an identity program challenging relative to similar exercises in the corporate world. Many of the actors who plan or evaluate BRT identity are not familiar with the process behind the development, or the demands of maintaining such an identity.

- Accountability and competition for profits drive corporate identity-making exercises. In public-sector services, such as public transit, the cycle of accountability is not as linear, occurs over a much longer period, and is not as acutely driven by profitability to the degree that corporate counterparts may be.

- Creating an identity is a collaborative effort and ideally brings together experts from transportation, urban planning, marketing, and design with 
stakeholders (riders and potential riders). The multidisciplinary nature of such an exercise makes difficult an already complex endeavor, especially when paths of communication or workflows are not in place and may be more challenging to establish.

- Procedure and process among traditionally unrelated fields (e.g., graphic design and transportation planning) may also create additional obstacles related to vocabulary and time management, which may hinder the longterm demands associated with creating and maintaining a viable identity.

\section{Research Approach}

Our evaluation focuses on 22 existing BRT systems at various stages of maturity: in revenue service, under construction, in development, or planned. The 22 systems selected $^{3}$ are intended to be representative and not a comprehensive evaluation of all BRT systems. In addition, some systems included in our original evaluation were pilot and test programs for BRT systems that were never fully realized, or that the parent agency opted to revert to traditional bus service. These systems, however, remain in the group we evaluated, as the lessons learned from such unsuccessful attempts are equally as valuable as the successes gleaned from fully realized BRT systems.

For each BRT system evaluated, we compiled information from government data, published inventories of U.S. BRT systems (Campbell 2004; TranSystems Corporation 2004; U.S. General Accounting Office 2001), collateral materials from BRT systems, and photographic and observational data. We also consulted the Federal Transit Administration (FTA) BRT website (U.S. Federal Transit Administration 2004), which supplies information on BRT projects funded through FTA demonstration programs. In addition, we visited operational BRT systems in Boston, Denver, Los Angeles, Orlando, Pittsburgh, Seattle, Toronto, and a pilot project in Washington, D.C., and we reviewed short-term and long-range planning documents supplied by officials from several transit agencies and by partners in the design firms engaged by transit agencies. We also conducted informal interviews with transit officials, bus drivers, and environmental graphic designers who specialize in the production of identity products for public transportation. Throughout this evaluation, we use best practice examples from our examination of 22 BRT systems. Rather than relying on only the best examples from the most heavily patronized-and possibly best funded-systems, we instead chose to discuss 
notable examples from many systems, even those from systems where the overall BRT IdP is less developed in comparison to others.

The design of BRT identity can be expressed as a function of visual identifiers, nominal identifiers, and color palette. We have adopted a modified version of Melewar's (2003) corporate identity taxonomy to evaluate the design elements of BRT IdP. Visual identifiers include logo and other visual elements; nominal identifiers include the "official" BRT system name or the colloquial parent system name (such as the "T" in Boston or the "El" in Chicago, for example) and the typography used to represent the name; color palette includes specific colors and a method for consistent use of color and color families on vehicles, shelters, and in collateral publications such as timetables, maps, and schedules.

Similarly, the principal factors that shape consumer perception (and presumed use) of public transit in general can be summarized in the acronym SCARCE: safety, comfort, accessibility, reliability, cost, and efficiency (Gray 1992). After a careful analysis of the SCARCE items, Wachs (1976) suggests that the most important service characteristics for encouraging people to ride transit are speed and convenience. Recent research finds that the SCARCE acronym, in addition to describing customer perception of a wide range of transit services, is also applicable to BRT; an analysis of onboard surveys of BRT riders in Orlando and Miami found that customers place a high value on frequency of service, comfort, travel time, and reliability of service (Baltes 2003).

\section{BRT IdP Assessment}

Our evaluation of 22 BRT systems yields a number of recurrent approaches to identity development or deployment. Though the 22 systems we evaluated represent only a small number of those planned and/or in revenue service, the analysis offered provides a common vector for further consideration as well as for future investigation.

\section{Visual Identifiers}

Bus shelter space, vehicle placards, and most recently entire vehicle exteriors have been considered a blank slate for graphic designers and advertisers (as well as graffiti artists) and command top advertising dollar (Heller 1999). Evidence suggests that advertising wraps on both buses and rail vehicles have significantly altered public perception of most transit operations (Jarzab, Lightbody, and Maeda 2002), and few could argue that buses as moving billboards are prime advertising real 
estate. However, observational data suggest that transit officials and designers of BRT systems are forgoing the sale of this prime advertising space and instead using the space to fully articulate BRT IdP and "sell" public transit and BRT instead of a commercial product or service. Similarly, BRT shelter spaces are usually uncluttered by advertising, so that BRT IdP does not compete among the visual noise of a typical busy streetscape.

BRT shelters and information kiosks typically include minimal aesthetics and signage that features high-contrast sans serif type and distinctive geometrics that are easy to see and read at a distance or in inclement weather (see Figure 2), and ensure maximum readability, especially for those unfamiliar with the local language or for those with memory and cognitive impairments. In Boston, Los Angeles, and Orlando, all BRT shelters contain information-rich kiosks that provide customers with audiovisual transit information (and also draw from sustainable solar power in Los Angeles).

Likewise, vehicle aesthetics are typically visually "clean" or uncomplicated in design, and often prominently feature a simple color palette and/or only one typeface. For example, Metro Rapid vehicles in Los Angeles are painted entirely in red and white and feature a heavyweight sans serif typeface that can be read easily at a distance or while the vehicle is in motion. ${ }^{4}$

Like vehicle and shelter aesthetics, the design and aesthetic consideration of BRT collateral products such as schedules and websites are visually streamlined and feature careful use of color and imagery. For example, Express! The Bus in Honolulu features thoughtfully designed and intuitive graphic user interfaces (Lidwell, Holden, and Butler 2003; Norman 2002).

Our observations support research that indicates that motorists and pedestrians are more likely to see, discern, and remember a clearly marked BRT vehicle in motion than a traditional local bus (with transit agency markings and typically advertising as well), which travels at slower speeds and makes more stops to collect and drop off passengers.

\section{Nominal Identifiers (BRT System Name and Logo)}

Name, logo, and service encompass the nominal identifiers of BRT IdP. Like the aforementioned graphic elements, BRT logos are evaluated by the public in terms of geometric form, color, explicit or implied message, and use of typography. Metro Rapid, for instance, incorporates the existing and highly recognizable " $M$ " associated with Los Angeles Metro service. Derivative nominal identifiers incorpo- 

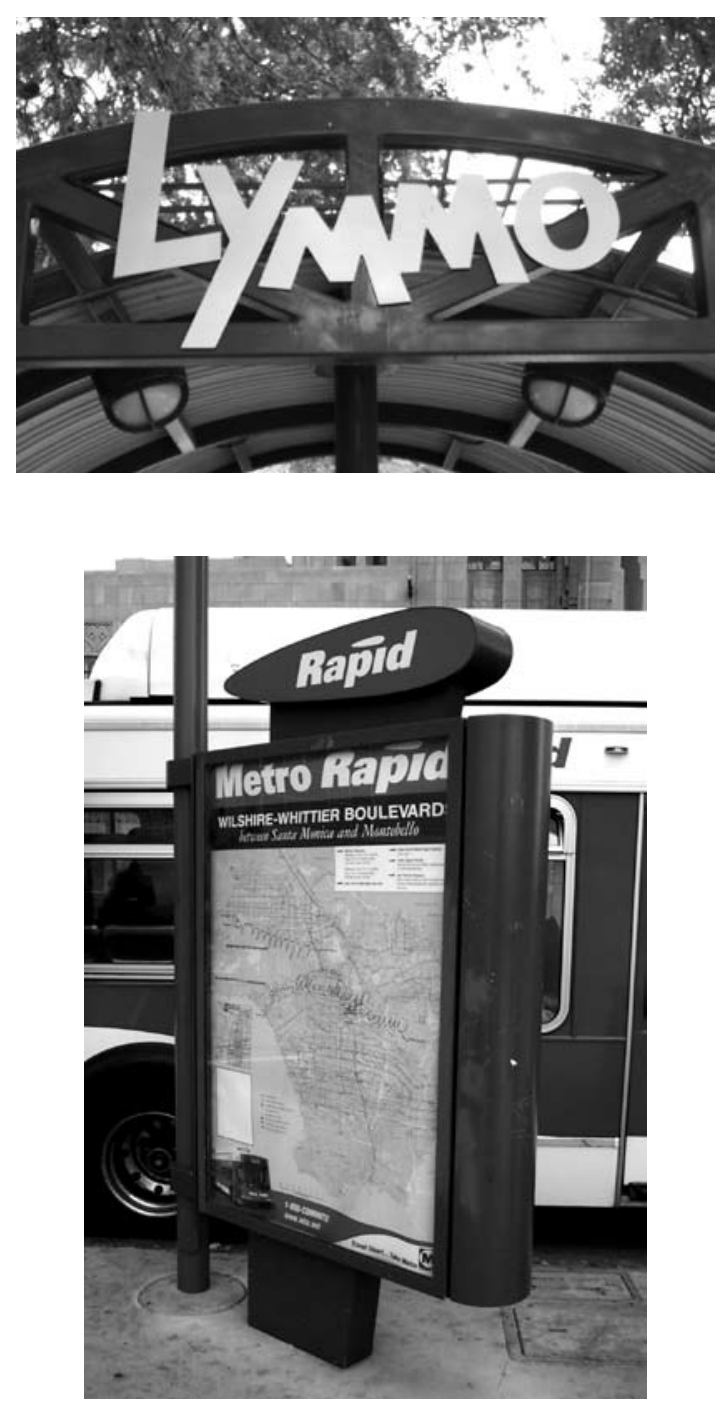

CMIIDI INF

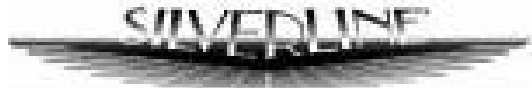

Source: Photos by authors, except Silver Line logo from MBTA.

Figure 2. BRT IdP Nominal Identifiers-Orlando Lymmo, Los Angeles Metro Rapid, Boston Silver Line 
rate existing elements such as color choice, typography, or letterforms into BRT IdP. For example, the Lymmo name borrows the "Ly" from its parent transit agency LYNX, and uses a similar (but distinct) typography and color scheme. Illustrations of the four sample BRT IdPs in Los Angeles, Boston, and Orlando, along with referential information about the identity of each parent transit agency is shown in Table 2.

Usually BRT logos and BRT IdP center around typography, and typographic letterforms commonly feature or form the BRT system name, such as the planned Albany GoBus! or Metro Rapid in Los Angeles. Rarely do logos used to convey BRT IdP include acronym-based names of parent transit agencies such as MBTA, LYNX, MTA, or NFTA. Terminology used in BRT names often connotes exclusivity and first-rate or premium service more so than the names of other services offered by parent transit agencies. For example, Silver Line in Boston, Lymmo (a playful moniker for limousine), and Express! The Bus denote "premium" service levels.

Linear elements connote movement, speed, direction, and/or connection. Most of the logos evaluated incorporate some sort of distinct linear element, or manipulation of typographic elements to imply linear movement, such as the silver ribbon stripe used to identify Boston Silver Line vehicles. This linearity ensures readability as the vehicles move at high speed and implies a sense of direction or speed when the vehicles are at rest. The elliptically dotted "i” in LA's Metro Rapid graphically reads as "in motion," both when vehicles are actually moving as well as stopped. The unique ellipse appears across the Metro Rapid system on vehicles, at shelters, and in collateral materials.

Frequently, BRT lines carry names that imply speed and freedom. For instance, use of rapid in the name Metro Rapid communicates to the user that Metro Rapid BRT service is faster than typical bus service. Other BRT IdPs that feature terms that imply speed include two proposed systems, Albany GoBus! and Detroit SpeedLink, and two systems in revenue service, the Vancouver B-Line and Phoenix Rapid. The conjunctive letters $X$ and $Y$ feature diagonal linear elements and are often rendered in such a manner to denote speed and direction-for example, the $X$ used in the Connextions West Busway in Pittsburgh and the $\mathrm{Y}$ used in the Lymmo BRT IdP in Orlando.

In some cases, place names or colloquial identifiers influence the name of BRT systems and feature prominently in BRT IdP. Examples include the Rio Hondo Connector in San Juan, the Phoenix Rapid, and the City-County Express in Hono- 


\section{Table 2. Comparison of BRT and Parent Transit Agency Identity Programs}

\begin{tabular}{|c|c|c|c|c|}
\hline \multirow{2}{*}{$\begin{array}{l}\text { BRT } \\
\text { System }\end{array}$} & Metro Rapid & Silver Line & San Pablo Rapid & Lymmo \\
\hline & Los Angeles, $\mathrm{CA}$ & Boston, MA & Alameda County, CA & Orlando, FL \\
\hline $\begin{array}{l}\text { BRT } \\
\text { Identity }\end{array}$ & 1 & & & \\
\hline $\begin{array}{l}\text { Parent } \\
\text { Transit } \\
\text { Agency }\end{array}$ & $\begin{array}{l}\text { Los Angeles County } \\
\text { Metropolitan } \\
\text { Transportation Authority }\end{array}$ & $\begin{array}{l}\text { Massachusetts Bay } \\
\text { Transportation } \\
\text { Authority }\end{array}$ & $\begin{array}{l}\text { Alameda County } \\
\text { Transit }\end{array}$ & $\begin{array}{l}\text { LYNX- } \\
\text { Central Florida } \\
\text { Regional Transportation } \\
\text { Authority }\end{array}$ \\
\hline $\begin{array}{l}\text { Transit } \\
\text { Agency } \\
\text { Identity }\end{array}$ & & & & \\
\hline Comments & $\begin{array}{l}\text { The Metro Rapid identity } \\
\text { is an additive or comple- } \\
\text { mentary identity that } \\
\text { capitalizes on the highly } \\
\text { recognizable M logo. }\end{array}$ & $\begin{array}{l}\text { The Silver Line identity } \\
\text { is carefully integrated } \\
\text { into the subway identity } \\
\text { program, but not the } \\
\text { overall MBTA identity. }\end{array}$ & & $\begin{array}{l}\text { A derivative but } \\
\text { separate identity, } \\
\text { Lymmo is closely } \\
\text { linked to LYNX and } \\
\text { to LYNX and } \\
\text { uses a similar logotype } \\
\text { and color palette. }\end{array}$ \\
\hline
\end{tabular}

All images by authors, except San Pablo Rapid, courtesy of Alameda County Transit. Logos from respective transit agencies. 
lulu, which has the added feature of communicating the regional scope of the BRT system.

\section{Color Palette}

Of the three design segments we evaluated, the use of color and color palette is perhaps the most complex. Our evidence indicates that mature BRT systems, such as Metro Rapid and Silver Line, make use of a well-defined, simple color palette that distinguishes BRT service from local bus service. In both Boston and Los Angeles, the color palette appears on vehicles, stations, and in collateral materials, such as timetables, system maps, and websites. Shelter spaces are uncluttered by advertising, and color is used to highlight positive and distinct features of BRT and to strengthen public perception of BRT and recognition of the BRT IdP. BRT shelters in Boston and Los Angeles use architecturally distinctive brushed steel canopies trimmed with silver (in Boston) and red (in Los Angeles). The spacious canopies used in Orlando are brightly painted and feature various colors of the Lymmo BRT IdP palette.

Transit officials clearly recognize the benefit in the careful use of a color palette for a BRT system that is distinct from the color palette used by the parent transit agency. Clearly, the use of color has proved popular in both Boston and Los Angeles. In conversations with transit officials in Los Angeles, we learned that the use of a distinct color palette for BRT has proved so effective that a "trickle down" effect has resulted in which non-BRT bus service has been redesigned to prominently exhibit a well-defined color palette that features a single color complemented by white or black. After the popular success of Metro Rapid, traditional buses serving local routes were painted bright orange and renamed Metro Local.

Less mature BRT, temporary service, and pilot programs employ color differently. Largely due to logistic reasons or economic constraints in these instances, the color palette selected to distinguish pilot BRT programs usually complements or mimics an existing color palette used by the parent transit agency. Because of this, in cases where BRT service is very new or temporary, the color palette used is not always distinct or unique from the parent. In some cases, such as the Lymmo in Orlando, parent service LYNX vehicles sometimes double as Lymmo BRT vehicles. Consequently, a fleet of vehicles designated by color as "Lymmo-only" would prove inefficient as the color palette used to identify Lymmo includes colors from the palette already used by the parent agency, LYNX. 
Similarly, planners of new BRT systems have reservations about using distinct color palettes on BRT vehicles, such as in the case of the GoBus!, planned by the CDTA in Albany. Planners of GoBus! expressed reservations about using green as the signature BRT color because they believe that specially branded or color-coded vehicles are less flexible in deployment and use, and could potentially cause confusion among riders when used on other routes (TranSystems 2004).

In cases where color is used to represent BRT service as distinct from the color palette used by the parent transit authority, the colors used are often "premium" metallic colors such as silver and gold, "hot" colors or shades of red and orange, or "unique" colors not usually associated with public transit such as neon shades or pink. Nearly all BRT identities evaluated use color palettes that provide high contrast between primary and secondary or tertiary colors.

\section{Conclusion}

When establishing BRT identity programs, transit officials have the opportunity to dispel a negative perception held by some that buses are categorically inferior to rail transit and automobiles. The effective development of an identity program can overcome the notion of buses as noisy, polluting, slow, and inconvenient. Identity development is vital to the success of new BRT service because it can simultaneously combat misperceptions and communicate specific service characteristics-speedy, quiet, and environmentally responsible buses that provide greater passenger comfort than traditional buses-that may make BRT more appealing to riders. We believe this to be especially true among status-conscious consumers in the United States for whom public transit is often considered a last resort. Likewise, new identity programs for BRT can help transit systems win public approval and increase the overall demand for public transit. Increased ridership translates into increased revenue, which can be used to help fund improvements to transit systems.

Because BRT does not introduce a new vehicle type, transit systems can, especially during pilot, trial, or initial introduction of BRT service, utilize existing resources (by designating, when needed, any bus for use on a BRT route) and avoid the expense of brand new and/or specialized vehicles, infrastructural equipment, systems, and facilities. Transit systems can allow ridership to respond to a service introduction or modification and they can begin earning revenue before contemplating infrastructural or service expansion by beginning service with lower cost investments. 
The General Accounting Office (U.S. General Accounting Office 2001) reports that a common perception detected by transit officials is the poor public image of bus service. Because of this, the stigma associated with traditional bus transit may make BRT less attractive to some potential riders. Identity elements, which can be deployed quickly at a reasonable cost, can shape a BRT IdP and improve public perception of bus transit.

BRT IdPs should strive to:

1. Use a color palette-one that clearly delineates the service as a signature offering-different from that of the parent transit agency.

2. Use nominal identifiers to underscore the following distinctive and attractive qualities of BRT:

- BRT is faster or more efficient than traditional bus service or automobile travel.

- BRT is more convenient.

- BRT is less expensive and easier than driving and parking.

- BRT can alleviate traffic congestion.

- BRT is an economic alternative to automobile ownership.

- BRT better protects the natural environment from automobile pollution.

3. Employ visual identifiers that are clear, distinct, and add value to transit facilities and streetscapes, as well as provide functional ease of use to riders regardless of age, physical ability, or cognitive ability. Visual identifiers that are high in contrast ensure readability from a distance, and allow for maximum decision-making time by all riders and potential riders. Visual identifiers that are simple to remember aid travelers unfamiliar with local service offerings or local language as well as those with cognitive or memory impairments.

4. Integrate with long-term strategic marketing and advertising plans to maximize any investments made.

Carefully planned and deployed BRT IdP can provide significant returns on investment relative to more common but less structured marketing or advertising campaigns. BRT IdP requires long-term investment and capital resources and is not a "quick-fix," silver bullet solution. A well-planned, consistently deployed, and carefully managed BRT IdP can help to change the public perception of public transit over time. 
Despite the potential short- and long-term benefits that can be realized from establishing identity programs, we find it somewhat difficult to envision the broad changes that would be required of transit officials to begin undertaking consumerdriven identity development supported by marketing (Lovelock 1973). However, the very future of public transit might depend on such creative and innovative approaches, as evidenced by a New York Times article that reports the Metropolitan Transportation Authority's proposal to sell naming rights-as a strategy to reduce the authority's enormous deficits - to transportation facilities in the New York City metropolitan region (Luo 2004). Conducting research for, developing, and implementing identity programs may be an unfamiliar practice for transit officials who tend to focus on operations, engineering, and finance. According to Bond, "It may be difficult to think of the monolithic transit industry as a culture that responds easily to change" because of its failure to "understand the environment of change and the need for innovations" (1984, p. 39). Similarly, Oram and Stark (1996, p. 77) conclude that transit systems have uncertain experiences with marketing ventures and "tend to be either rigid and make no changes at all for several years or over experiment with lots of programs hoping that something sticks."

Our analysis leads us to conclude that above all BRT IdPs should communicate a community's vision and objectives for its public transit system (U.S. Federal Highway Administration 2003). Only together can individuals in a community collectively decide how public transit fits into growth and development scenarios for the city and region. This vision can soundly inform the development of an identity program. For example, elements of identity programs that cater to employment travel and commuting and special event and tourist travel can be appropriately emphasized in an identity program and deployed in ways that reinforce community objectives. At the very least, communities' objectives for their public transit systems would likely include abundant opportunities for access and mobility-for residents and visitors alike - that is safe and civilized.

Toward this end, BRT IdP must be designed to be scalable in terms of investment and deployment and to accommodate future expansion and changes. The opportunity to deploy components of BRT systems and BRT IdPs incrementally offers transit agencies flexibility, provided that both are designed with a degree of scalability in mind. Future research for BRT IdPs should focus on the functional usability of BRT IdP elements for a broad and diverse range of users, because if the BRT IdP is not usable, it will likely be ineffective. Future projects could also under- 
score the multidisciplinary underpinnings of BRT IdPs. Guidelines that engage design practitioners, transit managers, financial managers, policy-makers, usability experts, and transportation planners would help to create collaborations across disciplines and isolated sectors of the professions. A comprehensive and international inventory of transit identity programs, implementation methods, and the long-term effects of the programs could be useful for framing future research projects. Most importantly, we believe in the importance of research that quantifies how identity development or enhancement corresponds to changes in people's perception about bus service and influences ridership decisions.

\section{Acknowledgments}

An earlier version of this research was presented at the annual meeting of the Transportation Research Board held in January 2005 in Washington, D.C. The authors wish to thank Kelly Dixon, Amy Franjesevic, Ann Makowski, Zach Miller, Michael Saunders, Paul Sieminski, Timothy Papandreou, and Kristina Younger.

\section{Endnotes}

${ }^{1}$ Collectively, the elements that define transit identity facilitate the development of a specific "brand" through which brand loyalty and brand equity are developed. However, brands are built over time through consumer interaction with identity. This evaluation is concerned with the objective and communicative constructs used to communicate identity, and not with the long-term subjective and ephemeral constructs that constitute brand.

${ }^{2}$ An early proposal for improved bus service was developed in Chicago in 1937, and similar plans followed for Washington, D.C., St. Louis, and Milwaukee (Levinson et al. 2002). The proposals generally called for bus service along transit ways or on highway lanes designed to bring commuters to downtown areas, with the objective of improving bus travel time as city streets (and later highways) became increasingly congested. These and other plans and a report entitled "Transportation and Parking for Tomorrow's Cities" (U.S. General Accounting Office 2001) recognized the advantages of bus transit in providing access and mobility for a diffuse population. Apart from express bus service and freeway flyers in certain cities, large-scale systemwide changes to bus service proposed in early plans were seldom implemented. Instead, cities began to compete for federal "new starts" funding for rail systems, especially throughout the 1970s, 1980s, and 1990s, and 
city bus service remained the status quo. Some researchers argue that the capital costs of these rail projects are disproportionately high compared to other transit investments (Pickrell 1992).

${ }^{3}$ The 22 systems evaluated include Silver Line, Boston; El Monte Busway and Metro Rapid, Los Angeles; Connextions West Busway, Pittsburgh; New Britain-Hartford Rapid Transit, Hartford; Southeast Corridor, Charlotte; Unnamed BRT Project (Lane Transit District), Eugene, Oregon; Express! The Bus, Honolulu; Trans2K, Oahu; South Miami Dade Busway, Miami; Line 22 Rapid Transit Corridor, Santa Clara; MAX, Las Vegas; Neighborhood Express Bus Route (NEBR), Chicago; Veirs Mills Road Bus Priority Project, Montgomery, Maryland; San Pablo Rapid, Alameda County, California; NY 5 BRT Project Go! Bus, Albany, New York; Lymmo, Orlando; Rio Hondo Connector, San Juan, Puerto Rico; Viva, Toronto, Ontario; Euclid Corridor, Cleveland; Big Blue Bus Rapid 3, Santa Monica; Downtown Express, Denver.

${ }^{4}$ Use of sans serif fonts in public transit identity is not without precedent; sans serif type designed in 1916 for London Transport by Edward Johnston was used for display work throughout the system (Baker and Robbins 1974).

\section{References}

Baker, T. C., and M. Robbins. 1974. A history of London transport: Passenger travel and the development of the metropolis. Vol. II. London: Allen \& Unwin.

Balmer, J. M. T., and A. Wilson. 1998. Corporate identity: There is more to it than meets the eye. International Studies of Management \& Organization 28 (3): 12.

Baltes, M. 2003. The importance customers place on specific service elements of bus rapid transit. Journal of Public Transportation 6 (4): 1-19.

Bierut, M., W. Drenttel, and S. Heller. 2002. Looking closer 4: Critical writings on graphic design. New York: Allworth Press, 61-63.

Bond, M. C. 1984. Marketing transit in the 1980s. Transitions: The Professional Transportation Quarterly: 39-49.

Campbell, J. 2004. Metro's BRT 25. Metro Magazine (April): 26-32.

Elmore-Yalch, R. 1988. Using market segmentation to increase transit ridership. Transit Cooperative Research Program Report No. 36. Washington, DC: National Academy Press. 
English, M. 1998. Designing identity. Gloucester, MA: Rockport Publishers.

Euclid Consultants (ICF Kaiser et al.). 1995. Cleveland dual hub corridor transitional analysis. Cleveland: Greater Cleveland Regional Transit Authority.

General Drafting Company and Massachusetts Bay Transportation Authority. 1977. MBTA map: Bus, rapid transit, commuter rail, 1977-1978. Boston: Massachusetts Bay Transportation Authority.

Gray, G. E. 1992. Perceptions of public transportation. In Public Transportation, G. E. Gray and L. A. Hoel, eds. Englewood Cliffs, NJ: Prentice-Hall.

Heller, S. 1999. Design literacy (continued): Understanding graphic design. New York: Allworth Press.

Heller, S., and K. Pomeroy. 1997. Design literacy: Understanding graphic design. New York: Allworth Press.

Hess, D. B., B. D. Taylor, and A. C. Yoh. 2005. Light rail lite or cost-effective improvements to bus service? Evaluating the costs of implementing bus rapid transit. Transportation Research Record: Journal of the Transportation Research Board 1927: 22-30.

Jarzab, J. T., J. Lightbody, and E. Maeda. 2002. Characteristics of bus rapid transit projects: An overview. Journal of Public Transportation 5 (2): 31-46.

Kemp, M. A. 1993. Transit fare issues in the 1990s-Where are we, and how did we get here? Presented at the Workshop on Transit Fare Policy and Management Research Needs and Priorities, Woods Hole, MA.

Levinson, H. S. 2003. Bus rapid transit. Washington, DC: Transportation Research Board.

Levinson, H. S., S. Zimmerman, J. Clinger, and S. Rutherford. 2002. Bus rapid transit: An overview. Journal of Public Transportation 5 (2): 1-30.

Lidwell, W., K. Holden, and J. Butler. 2003. Universal principles of design. Gloucester, MA: Rockport Publishers.

Lovelock, C. 1973. Consumer oriented approaches to marketing urban transit. Prepared for the Urban Mass Transportation Administration. Stanford, California, Stanford University Graduate School of Business.

Luo, M. 2004. Now a message from a sponsor of the subway? New York Times. July 27, 2004. 
Melewar, T. C. 2003. Determinants of the corporate identity construct: A review of the literature. Journal of Marketing Communications 9 (4): 195-220.

Norman, D. A. 2002. The design of everyday things. New York: Basic Books.

Olins, W. 1978. The corporate personality: An inquiry into the nature of corporate identity. New York: Mayflower Books.

Olins, W. 1990. Corporate identity: Making business strategy visible through design. Boston, MA: Harvard Business School Press.

Oram, R. L., and S. Stark. 1996. Surprise, surprise: Infrequent riders are a key to new transit ridership and revenue. Presented at the Annual Meeting of the Transportation Research Board, Washington, DC.

Pickrell, D. 1992. A desire named streetcar: Fantasy and fact in rail transit planning. Journal of the American Planning Association 58 (2): 158-176.

Polzin, S. E., and M. R. Baltes. 2002. Bus rapid transit: A viable alternative? Journal of Public Transportation 5 (2): 47-70.

Price Waterhouse. 1998. Funding strategies for public transportation. Volume 1: Final Report. Washington, DC: Transportation Research Board, National Academy of Sciences.

Pucher, J. 2001. Renaissance of public transport in the United States? Transportation Quarterly 56 (1): 33-49.

Reinke, D. 1988. Recent changes in BART patronage: Some findings on fare elasticities. Transportation Research Record 1165: 115-121.

Rosenbloom, S. 1998. Transit markets of the future: The challenge of change. Transit Cooperative Research Program. Washington, DC: Transportation Research Board, National Academy of Sciences.

Schrag, Z. M. 2001. Building the Washington Metro: An online exhibit.

Sislak, K. G. 2000. Bus rapid transit as a substitute for light rail transit: A tale of two cities. Presented at the APTA/TRB 8th Joint Conference on Light Rail Transit. Washington, DC: American Public Transportation Association and Transportation Research Board.

Transit Cooperative Research Program. 2003. Bus rapid transit. Vol. 1: Case studies in bus rapid transit. TCRP Report No. 90. Washington, DC: Transportation Research Board. 
TranSystems Corporation. 2004. Memorandum. Kristina Younger, Anne Benware, Sandy Misiewicz. Albany, NY.

U.S. Federal Highway Administration. 2003. MUTCD 2003: Manual on uniform traffic control devices. Washington, DC, U.S. Dept. of Transportation Federal Highway Administration Bureau of Transportation Statistics.

U.S. Federal Transit Administration. 2004. Bus rapid transit exchange website. http://knowledge.fhwa.dot.gov/fta/brt.nsf/home/.

U.S. General Accounting Office. 2001. Report to congressional requesters: Mass transit-bus rapid transit shows promise. Washington, DC: U.S. General Accounting Office.

Wachs, M. 1976. Consumer attitudes toward transit service: An interpretive review. Journal of the American Institute of Planners 42 (1): 96-104.

Wilbur Smith Associates. 1999. Nashville urban core light rail analysis. Nashville, TN: Nashville Metropolitan Transit Authority.

\section{About the Authors}

Daniel Baldwin Hess (dbhess@ap.buffalo.edu) is assistant professor in the Department of Urban and Regional Planning at the University at Buffalo. He was awarded a Dwight D. Eisenhower Fellowship for transportation research from the Federal Highway Administration. His research centers on public transit operations and finance and the interaction between travel behavior and urban form.

Alex Bitterman (alex.bittermman@rit.edu) is assistant professor in the School of Design in the College of Imaging Arts and Sciences at Rochester Institute of Technology. He is an expert in place branding and universal design, and one track of his current research evaluates the effectiveness, typology, and functional usability of identity programs for public transit systems and urban environments. 